\title{
Creation of Digital Ecosystem in the Context of Region Sustainable Industrialization
}

\author{
Larissa Bozhko ${ }^{1, *}$, Ramilya Sapanova ${ }^{1}$, Irina Shtykova $^{1}$, and Febry Wijayanti ${ }^{2,3}$ \\ ${ }^{1}$ Rudny Industrial Institute, 50 Let Oktyabrya Street, 38, 111500 Rudny, Kazakhstan \\ ${ }^{2}$ Ural Federal University, Mira street, 19, 620002 Yekaterinburg, Russia \\ ${ }^{3}$ Universitas Negeri Malang, 603105 Malang, Indonesia
}

\begin{abstract}
This paper presents features, approaches and institutional conditions, implications of digital technologies focused on the sustainable industrial development of the regional economy. The objective of the study is to analyse possibilities of the practical implementation of measures on digital ecosystem creation of separate region, Kostanay Region of the Republic of Kazakhstan, the industrial region of country having a certain innovation potential. This paper uses scientific methods of enquiry, statistical data and mathematical modelling in economics. In the result of study digital technology development priorities at the national level were established and the digitalization impact on the regional development was emphasised. The empirical analysis basis served the results of studies conducted within R\&D "Developing the Government Regulation Policy on Accelerated Clustering of Industrial Regions" conducted under the grant financing of Ministry of Education and Science of the Republic of Kazakhstan.
\end{abstract}

\section{Introduction}

The pandemic speed up global trends, including the digitalization increased rhythm, the grown uncertainty on territories' status, the necessity of new marketing solutions and the demand for the smart development model. Regions of Kazakhstan differently addressed the current challenge, showing the shady readiness to the rethinking of information role in the business and the society.

During the COVID-19 pandemic revealed shortcomings of digitalization processes, many national and regional programmes showed their limitedness. Not all regions were ready for the fast transition to digital technologies. Moreover, it can be stated the low level of information and communication infrastructure integrating territories into the common information space; insufficient ability of regions to model, integrate and open the access to intellectual digital resources.

The coronavirus pandemic also allowed to acknowledge the disunity of digitalization and spatial development priorities. The different degree of digital technology implementation in big cities, monotowns and rural settlements resulted in the disbalance and the amputation of early positive effects.

* Corresponding author: bozhkoll70@gmail.com 
The issue of stimulating activity in sphere of smart technology implementation remains the urgent challenge for Kazakh region. Currently, state support measures for innovative enterprises are taken, however, the dynamics of enterprise involvement into innovative activities shows that major changes have not been reached yet.

The concrete success in digital technology implementation is shown by industrial enterprises that have quickly adjusted and got used to operate in terms of the pandemic. Considering the gradual relief of restrictions in Kazakhstan, the business environment became easier, provided that the initial "shock" has left and at the moment major companies digitalize their business processes to the maximum.

It promotes the development of innovative environment where the progress in sphere of new technologies becomes the key factor for implementation of the Guidelines of World Summit on the Information Society (WSIS) and the 2030 Agenda for Sustainable Development; and as expected the achievement of Goal 9: Industry, Innovation, and Infrastructure.

The objective of study is to analyse possibilities of the practical implementation of measures on digital ecosystem creation of separate region, Kostanay Region of the Republic of Kazakhstan, the industrial region of country having a certain innovation potential.

\section{Materials and methods}

The study dataset of digitalization impact on regional development can be divided into several groups.

Firstly, works A. D'Auria, M. Tregua, and M.C. Vallejo-Martos are devoted to the analysis of state participation in the development of smart territory project, reflecting the impact of smart city concept implementation on social and economic position of local communities [1]. M. Angelidou discusses which factors affect the selection of smart region support model, characterizes options of such project development strategies [2]. A. Meijer and M.P.R. Bolivar show the interrelation of national and local policies with regard to smart territory projects [3]. There are papers, which authors analyse how the smart territory concept implementation allows to achieve global and national development goals. Thus, I. Turgel, L. Bozhko, E. Ulyanova, \& A. Khabdullin [4] discuss possibilities of the smart city technology use for achieving the global goals in sphere of environment protection. S. Praharaj, J. H. Han, and S. Hawken substantiate the necessity of smart cities' support in order to achieve the country innovative development goals [5].

Secondly, researchers emphasise that the digitalization causes the management process optimization, the competitiveness growth in every sector of economy [6]. Studies devoted to sectoral and industrial researches prove that the digital technology impact on efficiency and sustainability of the industrial sector will grow according to the "Industry 4.0" concept [7].

Thirdly, studies at microlevel show that the digitalization is the gamechanger for the business ecosystem offering unparalleled opportunities for entrepreneurship. Digital platform opportunities have positive impact on companies' economic effects [7].

Fourthly, works of S. Kraus, C. Richter, S. Papagiannidis and S. Durst [9] reveal the role of clusters in the smart region development and smart regions are considered as the cluster development accelerators.

In the course of study were used general scientific methods of enquiry (scientific study analysis, statistical data and mathematical modelling in economics). The study information based is comprised by documents of legislative government bodies, statutory documents of the Republic of Kazakhstan and regional development programmes. 


\section{Results and Discussion}

The digital ecosystem policy allows Kazakhstan to fit into the current international agenda on the achievement of global sustainable development goals. The implementation of smart region projects as such is the part of large-scale agenda in the development sphere; the central place of which is regained by three interrelated elements of sustainable development: economic growth, social integration and environment protection. The smart region projects directly determine the possibility to achieve the UN Sustainable Development Goal 9: Industry, Innovation, and Infrastructure. On the other hand, specific smart region project implementation formats inside the country are significantly determined by the dependence from the previous development pathway, which harshness was ensured by the relative immovability of internal institutional structures.

The Global ICT Regulatory Outlook 2020 states that the CIS region has reached certain progress, but statutory frameworks develop slower; since 2007 annually calculated mean values by region have being constantly falling behind the global values.

The background for the digital space creation in the Republic of Kazakhstan were established in 1997, in the Address of the President of the Republic of Kazakhstan to the People of Kazakhstan "Kazakhstan 2030 Prosperity, Security and Ever Growing Welfare of All the Kazakhstanis" that mentioned the necessity of "creation in the first place of the own, independent and effective system of telecommunication services". The trend towards the modern information and communications space creation is reflected in the Republic of Kazakhstan Strategy Development Plan until 2020. The information society concept was fully reflected in the State Programme "Informational Kazakhstan-2020" in 2013.

In 2017 the Address of the President of the Republic of Kazakhstan to the Nation of Kazakhstan "Third Modernization of Kazakhstan: Global Competitiveness" stated that it is required to bank on the sunrise sector development. Therefore, the Government of Kazakhstan was tasked to develop and approve the separate programme "Digital Kazakhstan".

In parallel with the "Smart City" incentive development, the country implements the State Policy on stimulating digital technology implementation in the industry. The significance of digital technologies for the industry development is reflected in the State Programme of Industrial and Innovative Development of the Republic of Kazakhstan for 2020-2025 (SPIID) In the current terms of postindustrial economy development, the Acceleration Programme "Smart Industry" becomes the most topical; it state the necessity of high-tech informational and process platform development: "IT of Mining and Metallurgical Complex" and "IT of Manufacturing Industries" for primary and supporting processes in mining, metallurgical and manufacturing industries.

The SPIID execution plan provides that for state support measures directed to cluster incentive development were allocated $18643.7 \mathrm{MM}$ tenge that amounts to $2.3 \%$ of the total funding of this programme.

The object of research is Kostanay Region, the region with significant innovative potential, which industry provides a considerable contribution to the GDP of the Republic of Kazakhstan. The most attractive sector for investment is the mining industry and quarrying (34.6\% of total capital investments).

In order to assess the creation of digital ecosystem in Kostanay Region, the existing situation shall be analysed. During 2015-2019 the number of organizations using special software tools of all types has significantly increased. The considerable growth is observed in the complex integrated system segment. Regional mining companies use complex integrated systems, such as ERP, CRM and SCM enabling the automation of key business processes. 
There is an increase of regional organizations' expenses on information and communication technologies (the growth rate in 2019 amounted to $122 \%$ to the level of 2015). The share of expenses on cloud services' purchase increases upon the decrease of expenses on equipment purchase evidencing the proper equipment capability of regional organizations. The upward trend of organizations using global information networks is clear. If the number of organizations that used Internet has increased from 3339 in 205 to 4162 in 2019, then the number of organizations that use business support systems on the basis of Internet technologies went up one-and-a-half times.

The available interorganizational digital transformation is evidenced by the two-fold increase (in comparison to 2015) of Intranet and Extranet use demonstrating the growth of business maturity level, its focus on qualitative parameters' growth and the information exchange speed-up.

The number of enterprises that use informational portals and websites has considerably increased. At the moment, the availability of corporate website becomes a common standard of business activities.

The following indices increased: the share of households with mobile broadband Internet access (on 16\% to 2015); the number of retail online orders (by 5 times to 2015), the number of wire transfers using digital technologies (by 2 times to 2015). The number of regional organizations that use Internet for communication with suppliers and customers has increased evidencing the intensive development of regional Internet trading.

In the result of study, it can be concluded that the biggest share of digitalization level in the region belongs to the large business showing the level of innovative activity $44.8 \%$, that almost twice bigger that the activity of small and medium business.

The most important projects implemented by the large business region are: "Smart quarry" (JSC “SSGPO”), Process Modernization (JSC “Kostanay Minerals"), ERP system Deployment (JSC "Kazakhstan Aluminium", Krasnooktyabrskoye Bauxitic Mine Management) that are based on the modern software products' use (Modular, GIS Surpac, GIS MineSched, MES, ERP, K-MINE, SIMULIA, etc.).

The conducted analysis has shown that the most perspective "point of growth" in the region can be the mining and metallurgical industry that shall be considered as the foundation for the smart production development.

For example, the implementation of "Smart quarry" project by JSC "SSGPO" will ensure the increase in labour productivity on $10 \%$ and the achieved economic benefit is 9.9 bn tenge by $2021,12.8$ bn. tenge by 2025 . The anticipated economic benefit of process modernization project implementation by JSC "Kostanay Minerals"), will amount $1.0 \mathrm{bn}$. tenge per year. In general, the forecast economic benefit of the Kazakh mining and metallurgical complex digitalization will reach 340.7 bn. tenge in 2025 .

The development of digital economy institutions in the Kostanay region industry complex will facilitate the use of cluster incentives. Clusters are designed to further promote innovations, industry development, growth of regional economy efficiency. The convergence of regions and smart clusters is considered as the possible quick overcoming of crisis events in economy and ensuring sustainable development. The region digitalization upon its competent application is the most realistic method of smart technology implementation in terms of financing, management efficiency improvement, creation of new services and content, which are highly-demanded and create the added value.

In the result of the analysis of dependence between expenses of regional enterprises on information and communication technologies and the number of employees possessing computer technologies and working remotely, the following dual linear regression equation was obtained:

$$
y=63.3585 x+2329906.8168
$$


Where, $\mathrm{y}$ - expenses of regional enterprises on information and communication technologies; $\mathrm{x}-$ the number of employees possessing computer technologies and working remotely.

The equation parameters were evaluated using the least square method. The test of equation statistical significance was carried out using the determination coefficient and the Fisher's criterion. It was established that in the studied situation only $40.51 \%$ of total yvariability is explained by $\mathrm{x}$-variations. It was also established that the model parameters are statistically insignificant. The share of expenses on employee training, IT competence development in the ICT expenses is minor. The lack of specialists with knowledge in the sphere of process issues solution and IT competences is the bottleneck of all regional companies.

The solution of this issue appears in the creation of Smart Cluster in Kostanay region that will provide the cooperation of mining companies with technology vendors, local business, universities and scientific institutes. The important chain of the Smart Cluster functioning shall become technology vendors due to innovation solution of which principles of operation, cooperation and communication are changing worldwide. The cooperation of vendors, mining companies and local universities will allow to arrange training of personnel with corresponding IT competences and skills of work with modern process informational solutions.

\section{Conclusions}

Based in the study findings the following conclusions can be made:

- The wealth of scientific works devoted to the specifics of digital technology implementation and the role of state in this process has formed;

- The continuity of programme documents in sphere of digitalization is observed in the Republic of Kazakhstan. The implementation of "Smart City" and "Smart Industry" projects is regulated by national programmes for digitalization and industrial and innovative development;

- The conducted analysis of digital technology in Kostanay region showed that the major role in the sustainable industrialization belongs to mining companies;

- The background for digital ecosystem formation was identified in Kostanay region, including the development of Smart Cluster providing the cooperation of mining companies with technology vendors, local business, universities and scientific institutes.

\section{References}

1. D’Auria, M. Tregua, M.C. Vallejo-Martos, Sustainability, 10(8), 2642 (2018)

2. M. Angelidou, Cities, 41, S3 (2014)

3. A. Meijer, M.P.R. Bolivar, International review of administrative sciences, 82(2), 392 (2016)

4. I. Turgel, L. Bozhko, E. Ulyanova, A. Khabdullin, Environmental and Climate Technologies, 23(2), 148 (2019)

5. S. Praharaj, J. H. Han, S. Hawken, Sustainable Development Studies, 1

6. K. N. Gorlov, M.V. Ilyicheva, Liberal Sciencies (2018)

7. D. Alaverdyan, F. Kučera, M. Horák. International Journal of Entrepreneurial Knowledge, 6, 30 (2018)

8. S. Hajduk, Business, Management and Education, 14, 34 (2016) 
9. S. Kraus, C. Richter, S. Papagiannidis, S. Durst, Creativity and Innovation Management, 24(4), 601 (2015) 